\title{
O Programa Bolsa Família e seus beneficiários na opinião pública brasileira
}

\author{
Pedro Santos Mundim ${ }^{1}$ (ib \\ Robert Vidigal ${ }^{2}$ \\ Fernando Canto Michelotti ${ }^{3}$ \\ André Jácomo de Paula Pinto ${ }^{4}$ (D)
}

\begin{abstract}
O artigo analisa como os brasileiros se posicionam em relação ao Programa Bolsa Família (PBF) e seus beneficiários. Os dados são de uma pesquisa nacional de opinião pública encomendada pela Secretaria de Comunicação Social da Presidência da República (Secom-PR). Resultados de um modelo logístico multinomial sobre as chances de apoio ao PBF mostraram que elas crescem com a avaliação positiva do governo federal, o nível de informação sobre o programa e o contato com beneficiários, mas caem com o aumento da escolaridade, da renda familiar e do nível de individualismo dos entrevistados. Ambivalências aparecem quando as análises se voltam para as opiniões sobre a gestão do Bolsa Família e seus beneficiários em particular. Regressões via mínimos quadrados ordinários (MQO), estimadas para avaliar as opiniões sobre os impactos positivos do PBF, a suposta falta de controle do programa e os beneficiários, mostraram que possuir mais conhecimento sobre 0 programa não diminui as visões negativas sobre os beneficiários ou as críticas em relação ao seu controle. De modo surpreendente, essas visões críticas estão presentes mesmo entre grupos de pessoas que teriam maiores chances de receber os recursos do Bolsa Família, como os menos escolarizados, não brancos e moradores do Nordeste.
\end{abstract}

Palavras-chave: Bolsa Família; opinião pública; individualismo; autointeresse econômico; atitudes raciais

\section{Introdução}

O Bolsa Família é um programa de transferência de renda com condicionalidades, cujo principal objetivo é combater a pobreza no Brasil ${ }^{5}$. Desde 2003, mais de 14 milhões

\footnotetext{
1 Universidade Federal de Goiás, Faculdade de Ciências Sociais, Goiânia, GO, Brasil.

E-mail: <psmundim@yahoo.com.br>.

2 Stony Brook University. Nova York (NY), Estados Unidos. E-mail: <robertleehc@gmail.com>.

3 Ministério da Saúde. Brasília, DF, Brasil. E-mail: <fcmichelotti@gmail.com>.

${ }^{4}$ Centro Universitário do Distrito Federal (UDF). Brasília, DF, Brasil. E-mail: <jacomo.andre@gmail.com>.

5 Algumas das condicionalidades: matricular crianças e adolescentes de 6 a 15 anos; garantir frequência escolar mínima de 85\%; vacinar crianças de menos de 7 anos; participar de programas de orientação de
} 
de famílias foram atendidas ${ }^{6}$. Embora as pesquisas que medem a eficácia de suas políticas apresentem resultados positivos nas áreas de saúde, educação ou renda (Soares, Ribas e Osório, 2007; Soares et al., 2010; Melo e Duarte, 2010; Lignani et al., 2010; Neto, 2010; Rocha, 2011; Hoffmann, 2013; Cavalcanti, Costa e Silva, 2013; Craveiro e Ximenes, 2013), a maneira como a opinião pública brasileira o enxerga ainda é controversa.

Por um lado, as pessoas concordam que a redução da pobreza é necessária. Por outro lado, discordam da atuação de um programa com transferência direta de recursos. Pesquisa de opinião pública nacional feita em 2008 mostrou que $72 \%$ dos brasileiros consideravam que o Programa Bolsa Família (PBF) trazia "mais boas coisas" para o Brasil, e $65 \%$ concordaram que ele "ajuda a combater a pobreza" no país. Existem outras diversas observações positivas (Castro et al., 2009). Mas a pesquisa também trouxe opiniões negativas: para 82\%, o PBF "inclui pessoas que não precisam"; para $67 \%$, "faz as pessoas se acomodarem e não quererem mais trabalhar"7; e para $56 \%$, "faz as pessoas quererem ter mais filhos".

O objetivo deste artigo é justamente explorar como os brasileiros se posicionam em relação ao PBF e seus beneficiários. Embora o programa seja objeto de inúmeras pesquisas sobre decisão do voto e eleições presidenciais (Nicolau e Peixoto, 2007; Soares e Terron, 2008; Terron e Soares, 2010; Zucco, 2008, 2015; Canêdo-Pinheiro, 2015; Corrêa, 2015, 2016), ainda conhecemos pouco sobre o que a opinião pública brasileira realmente pensa sobre ele e as pessoas que recebem seus recursos.

Este artigo é uma continuidade do trabalho de Castro et al. (2009), mas com avanços. Utilizamos os dados de uma pesquisa de opinião pública nacional encomendada ao Ibope Inteligência pela Assessoria de Pesquisa de Opinião Pública da Secretaria de Comunicação Social da Presidência da República (Secom-PR) e realizada entre os dias 21 e 28 de novembro de $2014^{8}$. O questionário trouxe um bloco de perguntas para captar a percepção dos brasileiros sobre o programa em diversos aspectos, desde o apoio e o nível de conhecimento relacionados a ele até as visões preconceituosas em relação aos beneficiários. O questionário da pesquisa também incluiu perguntas de avaliação do governo federal, de exposição à mídia e sobre valores, que permitem análises multivariadas.

\footnotetext{
saúde e nutrição para gestantes e crianças. Uma descrição detalhada do Bolsa Família encontra-se em Campello e Neri (2013) e Soares e Sátyro (2010).

${ }^{6}$ Não entraremos em discussões sobre o Bolsa Família ser uma derivação de programas implementados em governos anteriores ao PT ou algo inovador que caracteriza de maneira marcante o modo petista de implementar políticas públicas. Existem outros fóruns para esses debates.

7 Não é incomum, em conversas com críticos do PBF, ouvi-los chamar o programa de "bolsa preguiça". O artigo de Marques e Maia (2012) mostra como beneficiárias do PBF são afetadas por essas visões preconceituosas, mas também como reagem a elas.

8 Pesquisa quadrimestral de opinião pública da Secom-PR. Foram entrevistados 2.002 brasileiros de 16 anos ou mais. Procedimento amostral: conglomerado em três estágios, sendo os dois primeiros por sorteios probabilísticos dos municípios e dos setores censitários, e o terceiro por cotas de sexo, idade, escolaridade e ramo de atividade. Nível de confiança de $95 \%$ e erro de $\pm 2 \%$. Os relatórios das pesquisas estão disponíveis na página da Secom-PR na internet: <http://www.secom.gov.br/atuacao/pesquisa>. Acesso em: nov. 2019.
} 
O artigo está organizado da seguinte forma: na próxima seção, "Estado e políticas de bem-estar social e a opinião pública", apresentamos trabalhos que analisaram como a opinião pública se posiciona em relação a políticas de bem-estar social, de um modo geral, e de combate à pobreza, de maneira mais específica ${ }^{9}$. Acreditamos que, embora o PBF não tenha sido caracterizado como um programa de bem-estar social, essa qualificação é bastante adequada (Pires, 2013) ${ }^{10}$. Em seguida, em "Descrição dos dados", descrevemos o contexto de elaboração da pesquisa e os dados utilizados. Finalmente, em "O que explica o apoio ao PBF?", discutimos os resultados das análises multivariadas para o apoio ao PBF e para as opiniões sobre os resultados do programa, seu funcionamento e a imagem que se tem dos beneficiários.

Estimamos tanto um modelo logístico multinomial para avaliar os determinantes do apoio ao PBF quanto regressões via MQO (mínimos quadrados ordinários) para avaliar as opiniões sobre os impactos positivos do PBF, a suposta falta de controle do programa e a imagem que se tem dos seus beneficiários. Os resultados mostraram uma baixa ambivalência da opinião pública em relação ao apoio ao Bolsa Família. Por exemplo, encontrou-se uma correlação positiva com a avaliação do governo federal, com o nível de informação sobre o PBF e com o fato de se conhecer um beneficiário. Por outro lado, o aumento da escolaridade, da renda familiar mensal e do nível de individualismo dos entrevistados contribuem para a rejeição ao programa.

A ambivalência aparece quando as análises se voltam para as opiniões sobre os impactos positivos do PBF, a suposta falta de controle do programa e os seus beneficiários. Possuir mais conhecimento sobre o PBF não diminui as visões negativas sobre os beneficiários ou as críticas em relação ao seu controle. Isso sugere que as posições dos entrevistados sobre o programa são difíceis de mudar, mesmo com o repasse de informações. De modo surpreendente, essas críticas ao funcionamento e aos beneficiários estão presentes mesmo entre grupos de pessoas que teriam maiores chances de receber os recursos do Bolsa Família, como os menos escolarizados, não brancos e moradores do Nordeste.

\footnotetext{
${ }^{9}$ Não é nosso objetivo entrar nas discussões sobre a definição de Estado de bem-estar social ou bem-estar social. Isso já foi feito em outro lugar (Faria, 1998). Por isso, aceitamos a definição simples apresentada por Harold L. Wilensky em The welfare State and equality: structural and ideological roots (apud AuClaire, 1984, p. 139): um "conjunto de instituições e disposições sociais que buscam oferecer 'padrões governamentais de renda, nutrição, saúde, moradia e educação, garantidos a todo cidadão como um direito político, não como uma caridade"'.

10 Ver também a entrevista com Tereza Campello e Ana Fonseca, respectivamente ex-ministra e ex-secretária extraordinária para a Erradicação da Pobreza do Ministério do Desenvolvimento Social (MDS), órgão responsável pelo PBF: "O Brasil Sem Miséria será um programa de bem-estar social". Estado de S. Paulo, 7/5/2011. Disponível em: <http://politica.estadao.com.br/noticias/geral,o-brasil-sem-miseria-sera-umprograma-de-bem-estar-social,716242>. Acesso em: 18 abr. 2018.
} 


\section{Estado e políticas de bem-estar social e a opinião pública}

Não é difícil encontrar, no Brasil, textos que discutem, estudam e analisam o Estado de bem-estar social. Contudo, pode-se afirmar que inexistem estudos sobre como a opinião pública brasileira se posiciona em relação a programas ou políticas de combate à pobreza e de assistência social voltadas a garantir direitos políticos e sociais mínimos para a parcela mais desprotegida da população.

É possível demonstrar essa afirmação de uma maneira relativamente simples. Uma busca no Portal de Periódicos Capes em 3 de dezembro de 2018, com os filtros "periódicos revisados por pares" e "título" ativos e com os descritores "welfare state" e "public opinion", sem nenhuma restrição de data, encontrou 34 entradas. Ao permitir a busca "no assunto", esse número subiu para 75. Já uma busca com a mesma data e filtros, mas com os descritores "Estado de bem-estar social" e "opinião pública" não obteve qualquer entrada, seja na busca por "título", seja por "assunto"11.

Conhecer os fatores que influenciam o posicionamento da opinião pública sobre programas e políticas de combate à pobreza e assistência social é importante, porque essa relação tem consequências práticas. Estudos mostram que governos e formuladores de políticas públicas são responsivos às demandas e posicionamentos do público (Manza e Cook, 2002; Erikson, Mackuen e Stimson, 2002), e isso obviamente aplica-se aos princípios e programas de bem-estar social (Hasenfeld e Rafferty, 1989; Weaver, 2002).

Nos EUA, entre 1970 e 1980, o Estado de bem-estar social perdeu apoio junto à opinião pública. Essa queda veio acompanhada do aumento de um clima de animosidade para com as políticas de combate à desigualdade social, especialmente entre os conservadores. Os questionamentos voltavam-se, principalmente, para o "Estado inchado" e para as políticas de repasse de dinheiro às pessoas pobres, que, na visão dos críticos, recompensavam a dependência e penalizavam a iniciativa. Uma consequência prática desse movimento foi a eleição do ex-presidente Ronald Reagan em 1980, pelo Partido Republicano, que pouco fez para a ampliação desses programas (AuClaire, 1984; Skocpol, 1990, 1991).

Em seus estudos sobre opinião pública e Estado de bem-estar social, Gilens (1995, 1996b) argumenta que programas educacionais, de auxílio à saúde e benefícios aos idosos tendem a receber amplo apoio dos americanos. As oposições e ambivalências aparecem em relação às políticas que são limitadas aos pobres e que oferecem transferência direta ou em espécie de recursos. Nesse contexto, a literatura especializada tende a enfatizar três indicadores que influenciam as opiniões das pessoas sobre as políticas de bem-estar e combate à pobreza: o autointeresse, o individualismo e as atitudes raciais ou a cor.

\footnotetext{
11 Também fizemos outros tipos de busca. Utilizamos o descritor "Bolsa Família" em vez de "Estado de bemestar social". O único artigo recuperado pela busca foi o de Castro et al. (2009). Utilizamos, também, o descritor "pobreza" em vez de "Estado de bem-estar social". Nesse caso, foram recuperados 17 artigos. Mas após uma avaliação crítica e rigorosa, verificou-se que nenhum deles realizou testes empíricos com dados de surveys.
} 
O autointeresse se expressa de uma maneira bastante simples. Políticas de bemestar social são bancadas com recursos públicos. Os impostos pagos pelos contribuintes de maior renda são transferidos, direta ou indiretamente, a cidadãos ou grupos economicamente mais vulneráveis. Logo, e por razões óbvias, o apoio a essas políticas tende a ser maior entre as pessoas de menor renda, já que elas seriam suas principais beneficiárias. A oposição viria justamente dos contribuintes de renda média ou alta, que pagariam impostos mas não se beneficiariam diretamente dos programas, por não se enquadrarem no perfil de público-alvo (Williamson, 1974; AuClaire, 1984; Hasenfeld e Rafferty, 1989; Skocpol, 1990).

O individualismo remete à dimensão ideológica ou do sistema de crença dos indivíduos (Converse, 1964). Ele seria a manifestação de valores que enaltecem a "ética do trabalho", a recompensa pelo esforço individual e a pequena ou nula dependência da ajuda do Estado para o sucesso pessoal. Haveria, portanto, uma oposição entre a posse de tais valores e o apoio ao Estado de bem-estar social e às políticas de combate à pobreza e de ajuda aos menos privilegiados (Feldman e Zaller, 1992). Embora pareça que esses princípios se manifestem apenas em países como os EUA (Feldman, 1983), as análises apresentadas nos próximos itens mostraram que eles também encontram guarida entre muitos brasileiros.

Atitudes raciais não significam uma simples declaração de cor. Elas representam os valores que se manifestam em percepções de que negros e pobres seriam preguiçosos e os próprios culpados pela desigualdade, ou nas opiniões negativas em relação aos beneficiários de programas de bem-estar social. Por razões históricas, nos EUA e no Brasil existem políticas voltadas para diminuir diferenças de renda e escolaridade que atingem principalmente os negros, que compõem a maior parte dos pobres desses países. Por isso, a literatura mostra que pessoas com ressentimentos em relação a esse grupo teriam maior propensão a se oporem a essas políticas, e elas estão principalmente entre os brancos (Gilens, 1995, 1996b; Tuch e Hughes, 1996, 2011; DeSante, 2013).

\section{Descrição dos dados}

A pesquisa de opinião pública nacional da Secom-PR permitiu a criação de dois tipos de variáveis dependentes. A primeira mediu o apoio ao PBF: $62 \%$ dos entrevistadores eram a favor do programa, $21 \%$ contra e $16 \%$ nem a favor nem contra (espontânea). 0 segundo são índices derivados de dez frases sobre o PBF em que os entrevistados discordavam, assumiam uma posição neutra ou concordavam com o que era lido.

Foram criados três índices: de "impacto social" dos resultados percebidos do PBF; do nível de "preconceito" em relação aos beneficiários; e de crítica à suposta falta de "controle" do programa. O primeiro tem característica "positiva": quanto maior o valor, mais alto o nível de concordância com visões positivas sobre os resultados. Os demais têm 
características "negativas": quanto maiores os valores, mais altos os níveis de concordância com visões negativas sobre os beneficiários e o funcionamento do programa.

As frases encontram-se na Tabela 1:

Tabela 1

Distribuição do nível de concordância com frases associadas ao PBF e seus beneficiários (\%)

\begin{tabular}{|c|c|c|c|c|c|}
\hline & Discorda & Neutro & Concorda & NS/NR & $\mathbf{N}$ \\
\hline Melhorou a vida das pessoas pobres no Brasila. & 20 & 14 & 62 & 4 & 2002 \\
\hline Favorece a acomodação dos beneficiários ${ }^{\mathrm{b}}$. & 23 & 13 & 60 & 4 & 2002 \\
\hline Ajudou a reduzir a desigualdade no Brasila. & 33 & 13 & 50 & 4 & 2002 \\
\hline Incentiva as pessoas a terem mais filhos para receber o benefício ${ }^{b}$. & 33 & 13 & 50 & 4 & 2002 \\
\hline Ajudou na redução da pobreza no Brasila. & 28 & 13 & 55 & 4 & 2002 \\
\hline Aqueles que recebem o Bolsa Família ficam dependentes do governob. & 24 & 14 & 58 & 4 & 2002 \\
\hline Melhorou a vida das mulheres beneficiárias, pois são elas que recebem o dinheiroa. & 21 & 14 & 60 & 4 & 2002 \\
\hline Há pouco controle sobre quem deve de fato receber o programac. & 16 & 12 & 68 & 4 & 2002 \\
\hline Melhorou a vida das crianças, pois elas são incentivadas a ir para a escolaa. & 23 & 13 & 60 & 4 & 2002 \\
\hline Há pessoas que recebem o Bolsa Família, mas que não deveriam receberc. & 16 & 10 & 70 & 4 & 2002 \\
\hline
\end{tabular}

Fonte: Pesquisa Quadrimestral de Opinião Pública Secom-PR - novembro, 2014.

a Compõem o índice de impactos sociais.

b Compõem o índice de preconceito.

c Compõem o índice de controle do programa.

As visões negativas poderiam ter composto uma única medida? Embora uma análise fatorial exploratória tenha mostrado que sim, optamos por separá-las ${ }^{12}$. 0 índice de preconceito aponta para uma dimensão valorativa. O objetivo foi testar o nível de concordância com certos "mitos" ou falas pejorativas sobre os beneficiários que circulavam na sociedade, mesmo que não encontrassem respaldo nas análises empíricas (Campello, 2013). O índice de controle aponta para uma crítica operacional do PBF. Nesse sentido, como sugerem Feldman e Zaller (1992, p. 296): "essas preocupações não são simples aspectos alternativos de uma mesma atitude; (...) representam reservatórios de opinião um tanto independentes".

As estatísticas descritivas dos índices estão na Tabela 2:

Tabela 2

Estatísticas descritivas dos índices

\begin{tabular}{|l|c|c|c|c|c|c|}
\hline Índice & Média & Desvio-Padrão & Mínimo & Máximo & Alfa & N \\
\hline Impactos sociais & 11.73 & 3.24 & 5 & 15 & 0.817 & 1872 \\
\hline Preconceitos & 6.92 & 2.04 & 3 & 9 & 0.674 & 1881 \\
\hline Controles & 5.12 & 1.31 & 2 & 6 & 0.659 & 1905 \\
\hline
\end{tabular}

Fonte: Pesquisa Quadrimestral de Opinião Pública Secom-PR - novembro, 2014.

12 Os resultados dessa análise podem ser solicitados ao primeiro autor do artigo pelo e-mail <psmundim@ufg.br>. 
As variáveis de controle

O primeiro grupo de variáveis de controle contempla as características sociodemográficas dos entrevistados: cor, gênero, idade, escolaridade, renda familiar mensal e as regiões do país ondem eles residem ${ }^{13}$. Em grande parte dos trabalhos essas variáveis estão relacionadas à avaliação das políticas e programas de bem-estar social e combate à pobreza (AuClaire, 1984; Hasenfeld e Rafferty, 1989; Tuch e Hughes, 1996, 2011; Fox, 2004; DeSante, 2013; Gilens, 1995, 1996b).

As atitudes raciais sempre foram fatores importantes para explicar o apoio ou a rejeição às políticas de bem-estar social e de combate à pobreza, principalmente entre os brancos. A expectativa era encontrar uma correlação negativa entre o entrevistado declarar-se branco e as opiniões favoráveis ao PBF e beneficiários ${ }^{14}$. O mesmo pode-se dizer do grupo de idade. Gilens (1996b) argumenta que pessoas brancas e mais velhas podem acreditar que cortes nas políticas de bem-estar atenderiam melhor seu autointeresse. Fox (2004), por sua vez, interpreta essas relações como um efeito de coorte. Em contraposição às pessoas brancas e mais jovens, pessoas brancas e mais velhas teriam maior probabilidade de possuir estereótipos negativos sobre grupos minoritários, como os afro-americanos. Assim, quanto mais velho o entrevistado, menor a sua predisposição a opiniões positivas sobre o programa.

Tradicionalmente, a renda familiar mensal é utilizada como o indicador de autointeresse econômico. Embora esteja longe de ser ideal e apresentar limitações, ela "tem se mostrado a melhor medida objetiva de condição econômica para o propósito de acessar visões sobre bem-estar social e é virtualmente a única medida utilizada em estudos anteriores sobre o assunto" (Gilens, 1996b, p. 595). A expectativa era de que o aumento da renda dos entrevistados elevasse a probabilidade de reprovação do PBF e de visões mais críticas sobre ele. Esperava-se o mesmo da escolaridade, uma vez que estudos mostraram que ela reflete mais opiniões ligadas ao status socioeconômico do que apoio aos valores de igualdade (Hasenfeld e Rafferty, 1989; Jackman, 1978, 1981; Jackman e Muha, 1984).

Foram criadas três variáveis binárias para demarcar as regiões Nordeste, Sul e Sudeste ${ }^{15}$. Estudos sobre o voto nas eleições de 2006 a 2014 apontaram a correlação entre

\footnotetext{
13 A configuração das variáveis foi a seguinte: cor/raça branca; gênero homem e mulher; grupo de idade: de 16 a 24 anos, de 25 a 34, de 35 a 44, de 45 a 54 e acima de 55; escolaridade: sem instrução ou não frequentou escola, da $1^{a}$ à $4^{a}$ séries, da $5^{a}$ à $8^{a}$ séries, ensino médio e ensino superior; e renda familiar mensal: até 1 salário mínimo, de 1 a 2, de 2 a 5 e acima de 5; e regiões do país: Nordeste, Sul, Sudeste, Norte/Centro-Oeste.

14 Uma ressalva importante. Em seus trabalhos, Gilens (1995, 1996b) pôde utilizar questões sobre atitudes raciais em relação aos negros para medir a rejeição dos brancos às políticas de bem-estar social. Concordamos que essas seriam as medidas ideais. Mas, infelizmente, elas não estão disponíveis no questionário da pesquisa de opinião pública da Secom-PR.

$15 \mathrm{O}$ ideal seria criar indicadores binários que isolassem os efeitos das regiões Norte e Nordeste, principalmente. Mas, no procedimento amostral, o Ibope incluiu os estados do Norte e Centro-Oeste numa mesma medida.
} 
o PBF e o voto em Lula e Dilma, principalmente entre eleitores de municípios das regiões mais pobres (Soares e Terron, 2008; Hunter e Power, 2007; Zucco, 2008, 2013, 2015; Corrêa, 2015, 2016). Lício, Rennó e Castro (2009) mostraram que ser beneficiário do programa tinha, também, um efeito positivo na avaliação do governo federal. Esperavase, portanto, que moradores da região Nordeste estivessem mais inclinados a apoiar e avaliar positivamente o PBF, e a rejeitar visões negativas sobre seus resultados e beneficiários.

As variáveis políticas incluídas são a avaliação do governo federal numa escala que vai de péssimo a ótimo e um índice que buscou captar os valores individualistas dos entrevistados. Na época da pesquisa, a ex-presidente Dilma tinha $41 \%$ de avalição ótima ou boa, $37 \%$ de regular e $21 \%$ de ruim ou péssima. A primeira variável foi incluída pelo simples fato de o PBF ser o programa social mais importante dos governos petistas e por ser conhecida a sua importância para a eleição e reeleição dos ex-presidentes Lula e Dilma. Logo, entrevistados com avaliações mais positivas do governo federal tenderiam a apoiar o PBF e provavelmente teriam opiniões favoráveis aos beneficiários, por conta de uma "contaminação" da imagem do primeiro sobre a dos segundos.

O índice de individualismo foi criado a partir de três perguntas do questionário, em que os entrevistados eram forçados a escolher, entre duas frases, com qual concordavam mais. As frases contrapunham uma visão liberal clássica, de valorização da livre iniciativa, com uma visão mais assistencialista, a favor de maior presença do Estado na vida das pessoas ${ }^{16}$. Para cada uma das perguntas foi criada uma nova variável, sendo 1 para as respostas liberais e 0 para as demais, incluindo não sabe (NS) e não respondeu (NR). Elas foram somadas, constituindo-se um novo indicador com valor mínimo de zero, máximo de 3, média de 1.46, desvio-padrão de 0.99 e alfa de Cronbach de 0.373 .

A expectativa era de que pessoas com visões mais individualistas teriam maior probabilidade de reprovar o PBF e de serem mais críticas em relação ao programa e a seus beneficiários. Contudo, como ressaltou Feldman (1983, p. 26), elas poderiam apresentar ambivalência, pois "a percepção da falta de oportunidades iguais produz apoio aos programas que ajudam os necessitados ao mesmo tempo em que a ética de trabalho gera hostilidade para com aqueles que aceitam tais auxílios"17.

Foram incluídas variáveis binárias para captar se o entrevistado, ou alguém que mora com ele, era beneficiário do PBF. A expectativa era encontrar uma associação positiva

\footnotetext{
${ }^{16}$ As frases são: "Boa parte da pobreza está ligada à preguiça de pessoas que não querem trabalhar" (40\%) versus "Boa parte da pobreza está ligada à falta de oportunidades iguais para que todos possam subir na vida" (52\%); "Quanto menos eu depender do governo, melhor estará minha vida" (52\%) versus "quanto mais benefícios do governo eu tiver, melhor estará minha vida" (36\%); e "As pessoas precisam da ajuda do governo para melhorar de vida" (37\%) versus "As pessoas são capazes de melhorar de vida por si próprias, e a ajuda do governo acaba as deixando acomodadas" (54\%).

17 Como as políticas de bem-estar são governamentais, estamos cientes da importância da identificação partidária e da ideologia, medida de forma clássica, na avaliação desses programas. Contudo, por conta do seu objetivo institucional, as pesquisas da Secom-PR não podiam incluir menções a partidos políticos nos seus questionários, nem mesmo o da ex-presidente da República, nem perguntas sobre ideologia política. Por esse motivo essas duas variáveis não foram incluídas nos modelos apresentados neste artigo.
} 
entre receber recursos do programa com visões positivas sobre o programa. Por mais óbvias que essas relações pareçam ser, a expectativa com essas medidas também era avaliar o impacto do contato com os beneficiários. O trabalho de Fox (2004), por exemplo, mostrou que a percepção positiva dos brancos sobre a ética de trabalho dos latinoamericanos aumentava em estados com maior concentração desses imigrantes.

$O$ índice de conhecimento sobre o PBF foi pensado como uma espécie de indicador de atenção política (Zaller, 1992; Zaller e Price, 1993), capaz de captar o quanto os entrevistados se expuseram e absorveram informações sobre o programa. Ele foi derivado de uma bateria de quatro perguntas para medir o nível de conhecimento sobre os $\mathrm{PBF}^{18}$. Para cada uma delas foi criada uma nova variável, sendo 1 para as respostas certas e 0 para as respostas erradas, não sabe e não respondeu. Elas foram somadas, constituindose um novo indicador com valor mínimo de zero, máximo de 4, média de 1.954, desviopadrão de 1.067 e alfa de Cronbach de 0.382 .

Em relação a esse índice, esperava-se que, quanto mais informação uma pessoa tivesse sobre o PBF, menor seria a probabilidade de reprová-lo. Esse efeito positivo do maior acúmulo de informações ocorreria tanto por uma maior compreensão do PBF e seus benefícios sociais quanto por um efeito de coerção de visões preconceituosas.

Por fim, foram incluídas variáveis de exposição ao Jornal Nacional e aos portais de notícia ou redes sociais, derivadas da pergunta sobre qual meio de comunicação os entrevistados mais usam para se informar. A pergunta oferecia até duas opções de reposta, mas consideramos apenas a primeira. Cerca de 55\% dos entrevistados disseram que o meio que mais utilizavam para se informar era o principal telejornal da TV Globo, enquanto $10 \%$ responderam que eram os portais de notícia ou redes sociais.

Gilens (1996a) atestou como telejornais e revistas semanais norte-americanas retratavam, de um maneira exagerada, os pobres como sendo majoritariamente negros. Ele argumentou que esse enquadramento contribuiria para diminuir o apoio às políticas de combate à pobreza. No Brasil, estudos mostraram que a cobertura sobre o PBF em grandes veículos reproduzia visões de que ele era "assistencialista", "uma esmola", que criava dependência do governo e que, por isso, não converteria os "pobres em cidadãos", mas os tornaria "objeto de políticas" (Biroli e Mantovani, 2010; Marques, 2010; Marques e Maia, 2012). Portanto, a expectativa era de que as variáveis midiáticas tivessem tanto impacto negativo na aprovação do PBF quanto aumentassem as críticas ao programa e seus beneficiários.

\footnotetext{
18 As perguntas são: "Pelo que o(a) sr(a). sabe ou ouviu falar, quem é, de um modo geral, a pessoa responsável na família pelo recebimento do recurso do Bolsa Família?"; "Agora falando sobre as exigências as quais os beneficiários do Bolsa Família precisam cumprir para continuar recebendo o recurso, pelo que o(a) sr(a). sabe ou ouviu falar, qual é uma exigência feita pelo programa?"; "Agora falando sobre os limites dos valores recebidos do programa Bolsa Família, pelo que o(a) sr(a). sabe ou ouviu falar, como é estabelecido o valor que cada família recebe do programa?"; e "Pelo que o(a) sr(a). sabe ou ouviu falar, quais são os dois estados do Brasil que recebem mais recursos do programa Bolsa Família?".
} 


\section{O que explica o apoio ao PBF?}

A Tabela 3 traz os resultados de um modelo logístico multinomial para a aprovação do PBF. Para facilitar a comparação dos efeitos, todos os indicadores foram normalizados, ou seja, estão na escala de 0 a 1 :

Tabela 3

Determinantes do apoio ao PBF

\begin{tabular}{|c|c|c|}
\hline & Neutro & A favor \\
\hline Avaliação de governo federal & $\begin{array}{l}0.70 * \\
(0.31) \\
\end{array}$ & $\begin{array}{l}1.98^{*} \\
(0.26) \\
\end{array}$ \\
\hline Homem & $\begin{array}{c}0.27 \\
(0.17) \\
\end{array}$ & $\begin{array}{c}0.023 \\
(0.14) \\
\end{array}$ \\
\hline Escolaridade & $\begin{array}{c}-0.54 \\
(0.37)\end{array}$ & $\begin{array}{c}-1.55^{*} \\
(0.30)\end{array}$ \\
\hline Idade & $\begin{array}{c}-0.38 \\
(0.29) \\
\end{array}$ & $\begin{array}{c}-0.84 * \\
(0.24) \\
\end{array}$ \\
\hline Renda familiar mensal & $\begin{array}{c}-0.043 \\
(0.31)\end{array}$ & $\begin{array}{c}-0.57 * \\
(0.25)\end{array}$ \\
\hline Branca & $\begin{array}{c}0.27 \\
(0.17) \\
\end{array}$ & $\begin{array}{c}-0.084 \\
(0.14) \\
\end{array}$ \\
\hline Nordeste & $\begin{array}{l}1.21 * \\
(0.32)\end{array}$ & $\begin{array}{l}1.15^{*} \\
(0.24)\end{array}$ \\
\hline Sudeste & $\begin{array}{c}0.82 * \\
(0.26) \\
\end{array}$ & $\begin{array}{c}0.065 \\
(0.19) \\
\end{array}$ \\
\hline Sul & $\begin{array}{c}0.11 \\
(0.32) \\
\end{array}$ & $\begin{array}{l}-0.056 \\
(0.23) \\
\end{array}$ \\
\hline Jornal Nacional & $\begin{array}{c}0.39 * \\
(0.18) \\
\end{array}$ & $\begin{array}{c}0.42 * \\
(0.14) \\
\end{array}$ \\
\hline Internet (portais de notícias e redes sociais) & $\begin{array}{c}0.41 \\
(0.29)\end{array}$ & $\begin{array}{c}0.46 * \\
(0.23)\end{array}$ \\
\hline Conhecimento sobre o PBF & $\begin{array}{c}0.49 \\
(0.31) \\
\end{array}$ & $\begin{array}{l}1.30 * \\
(0.25) \\
\end{array}$ \\
\hline Beneficiário do PBF & $\begin{array}{c}-0.26 \\
(0.46)\end{array}$ & $\begin{array}{c}0.54 \\
(0.33)\end{array}$ \\
\hline Mora com beneficiário do PBF & $\begin{array}{c}0.16 \\
(0.41)\end{array}$ & $\begin{array}{l}1.20 * \\
(0.30) \\
\end{array}$ \\
\hline Individualismo & $\begin{array}{c}-1.47 * \\
(0.26)\end{array}$ & $\begin{array}{c}-1.58^{*} \\
(0.21)\end{array}$ \\
\hline Constante & $\begin{array}{c}-0.68 \\
(0.47)\end{array}$ & $\begin{array}{l}1.26 * \\
(0.37)\end{array}$ \\
\hline $\mathrm{N}$ & 1826 & \\
\hline Pseudo $\mathrm{R}^{2}$ & 0.150 & \\
\hline Log lik. & -1396.0 & \\
\hline $\mathrm{Chi}^{2}$ & 492.9 & \\
\hline
\end{tabular}

Fonte: Pesquisa Quadrimestral Secom-PR - novembro, 2014. Significância: * $p<0.05$.

Nota: Contra é a categoria de referência. Erros-padrão entre parênteses. 
Os resultados mostram coerência entre as expectativas teóricas e o comportamento das variáveis incluídas no modelo. O autointeresse econômico, medido pela renda familiar, apresentou uma correlação negativa com o apoio ao PBF. Observa-se um comportamento semelhante da escolaridade e da idade. Enquanto o grupo formado por pessoas de renda mais alta, mais escolarizadas e mais velhas tende a ser contra o programa, o formado por pessoas socioeconomicamente mais vulneráveis - e por isso mesmo mais propensas a serem beneficiárias - tende a apoiá-lo.

Esses efeitos encontram respaldo nas afirmações de Hasenfeld e Rafferty (1989, p. 1.041-1.042): "essas características de status [baixa renda, escolaridade e mais jovens] expõem as pessoas a dificuldades econômicas ou risco e elas olham para o Estado de bemestar social para protegê-las de grandes inseguranças e desigualdades". O autointeresse explicaria tanto a rejeição dos segmentos mais abastados ao PBF quanto a aprovação dos menos privilegiados. É provável, também, que a justificativa para a correlação positiva entre ser habitante do Nordeste, uma das regiões mais pobres do país, e ser a favor do programa se apoie em bases semelhantes.

Esses resultados merecem uma reflexão adicional sobre o efeito negativo da escolaridade. Tuch e Hughes (1996) argumentaram ser possível ampliar o apoio dos brancos a políticas de redução da desigualdade a partir de programas educacionais. Essa visão respalda a ideia de um suposto "efeito libertador" do aumento da educação (Jackman e Muha, 1984, p. 752-753), que poderia incutir nas pessoas visões mais democráticas, progressistas e tolerantes em relação aos grupos minoritários e ampliar o apoio a políticas de bem-estar social. Nesse sentido, não seria possível esperar um efeito positivo dessa variável no apoio ao PBF?

O estudo de Jackman (1981), contudo, se contrapõe a essa visão de um modo bastante pessimista. A autora concorda que as pessoas mais escolarizadas aprendem os princípios democráticos e tendem a apoiá-los "no abstrato". Mas também mostrou que elas não são mais propensas a respaldá-los do que as pessoas menos escolarizadas em situações concretas, como, por exemplo, no apoio a políticas de bem-estar social ou na maior tolerância em relação aos grupos minoritários. Isso se daria pela defesa dos valores e interesses de classe, que Ihes permitiria manter a condição privilegiada na qual se encontram na sociedade (Jackman e Muha, 1984).

Os dados sugerem um forte poder de influência do individualismo na rejeição ao PBF. À medida que o índice passa do apoio à presença do Estado na vida das pessoas para uma valorização da livre iniciativa, diminui a probabilidade de ser a favor do programa. Como já mostraram diversos estudos, sistemas de crença exercem forte influência sobre as opiniões e atitudes políticas (Campbell et al., 1967; Converse, 1964; Lewis-Beck et al., 2008). Não é surpresa, portanto, que esse indicador apresente uma clara associação com a aprovação do PBF.

A variável que indica a cor dos entrevistados não alcançou significância estatística, ainda que o sinal do coeficiente esteja na direção esperada. Esse resultado sugere uma 
limitação da medida utilizada. Gilens (1996a, 1995) e DeSante (2013), por exemplo, trabalharam com variáveis muito mais sofisticadas das percepções negativas e de ressentimentos em relação aos afro-americanos, para concluírem que a cor da pele ainda impacta negativamente o apoio a políticas de bem-estar social. Infelizmente, por uma limitação das perguntas do questionário da pesquisa utilizada, não há solução para esse caso.

As variáveis informacionais também se mostraram importantes para explicar o apoio, ou a rejeição, ao PBF. Os coeficientes dos indicadores de exposição ao Jornal Nacional e à internet estão contrários ao que previam os trabalhos sobre a cobertura midiática em relação ao programa, e não aumentam as chances de rejeição. Não possuímos dados para dizer se houve uma mudança no enquadramento sobre o PBF - de mais crítico e negativo para positivo - entre a produção dos estudos sobre a cobertura do programa em grandes veículos (Biroli e Mantovani, 2010; Marques, 2010; Marques e Maia, 2012) e o campo da pesquisa da Secom-PR, mas essa poderia ser uma explicação para o resultado encontrado.

Mas, ao falarmos de componentes informacionais, também podemos considerar o índice de conhecimento sobre o PBF. Conforme o esperado, a posse de informações sobre o programa aumenta a chance de ser favorável a ele. Isso sugere ao menos duas coisas: que as pessoas que o aprovam buscam ou têm mais informações sobre o PBF, ou que maior conhecimento sobre o programa melhora as chances de visões mais positivas pelo público, mesmo que a pessoa não seja diretamente afetada por ele.

Por fim, o PBF era o programa mais lembrado do governo federal, além de ser um dos fatores que explicam o sucesso eleitoral de Lula e Dilma. Seria improvável não encontrar uma correlação positiva entre as duas variáveis. O que os dados de novembro de 2014 deixam em aberto é se uma piora na avaliação da ex-presidente por razões externas às suas políticas sociais poderia contaminar a opinião dos brasileiros em relação ao programa.

A pesquisa quadrimestral de opinião pública da Secom-PR de abril de 2015 mostra que o governo federal tinha, nessa época, $13 \%$ de avaliação positiva e $60 \%$ de avaliação negativa, uma queda bastante expressiva em relação a novembro de 2014 , quando a avaliação positiva era de $41 \%$ e a negativa era de $21 \%$. Contudo, não se observou o mesmo movimento em relação ao PBF, pois $65 \%$ disseram ser a favor do programa e $25 \%$ contra. Esses dados descartam uma contaminação da opinião dos brasileiros sobre 0 programa pela avaliação do governo. É possível que o PBF tenha funcionado como uma das últimas fontes de resistência contra um aumento ainda maior da visão negativa dos brasileiros em relação ao governo federal observada em 2015. 


\section{Impactos, preconceitos e controles}

As estimativas do modelo de apoio ao PBF apresentaram resultados teoricamente coerentes. Uma explicação para isso é que se posicionar a favor ou contra um programa de bem-estar social, de um modo geral, tende a ser um comportamento menos conflituoso. No entanto, as ambivalências (Feldman e Zaller, 1992) surgem quando o assunto são as opiniões sobre os resultados do programa, seu funcionamento e a imagem que se tem dos beneficiários.

Foram estimados três modelos de regressão via mínimos quadrados ordinários, tendo como variáveis dependentes os índices de impactos, preconceitos e controles descritos anteriormente. É importante lembrar que o primeiro indicador é "positivo": quanto maior o seu valor, mais se concorda com os resultados positivos do PBF. Nos outros dois, é "negativo": quanto maiores os valores, mais se concorda com visões negativas dos beneficiários do programa e com críticas ao seu funcionamento.

Os resultados podem ser vistos na Tabela 4. Novamente, todos os indicadores estão na escala de 0 a 1.

Tabela 4

Determinantes das percepções sobre os resultados, o funcionamento e os beneficiários do PBF

\begin{tabular}{|l|c|c|c|}
\hline & Impactos & Preconceitos & Controles \\
\hline \multirow{2}{*}{ Avaliação de governo federal } & $\begin{array}{c}1.88^{*} \\
(0.29)\end{array}$ & $\begin{array}{c}-0.79 * \\
(0.19)\end{array}$ & $\begin{array}{c}-0.33^{*} \\
(0.12)\end{array}$ \\
\hline \multirow{2}{*}{ Homem } & 0.17 & 0.10 & 0.0057 \\
& $(0.15)$ & $(0.10)$ & $(0.06)$ \\
\hline \multirow{2}{*}{ Escolaridade } & $-1.65^{*}$ & 0.0076 & $-0.29 *$ \\
& $(0.31)$ & $(0.21)$ & $(0.13)$ \\
\hline \multirow{2}{*}{ Idade } & -0.19 & -0.071 & -0.21 \\
& $(0.27)$ & $(0.17)$ & $(0.11)$ \\
\hline \multirow{2}{*}{ Renda familiar mensal } & $-0.76 *$ & -0.30 & -0.13 \\
& $(0.26)$ & $(0.17)$ & $(0.11)$ \\
\hline \multirow{2}{*}{ Branca } & -0.045 & $-0.23^{*}$ & $-0.15^{*}$ \\
& $(0.16)$ & $(0.10)$ & $(0.07)$ \\
\hline \multirow{2}{*}{ Nordeste } & $1.66^{*}$ & $0.40 *$ & $0.41^{*}$ \\
& $(0.22)$ & $(0.15)$ & $(0.10)$ \\
\hline \multirow{2}{*}{ Sudeste } & 0.17 & $0.31^{*}$ & 0.15 \\
& $(0.23)$ & $(0.14)$ & $(0.10)$ \\
\hline \multirow{2}{*}{ Sul } & $0.90^{*}$ & 0.27 & $0.27^{*}$ \\
& $(0.28)$ & $(0.17)$ & $(0.12)$ \\
\hline \multirow{2}{*}{ Jornal Nacional } & $0.37^{*}$ & 0.14 & $0.14^{*}$ \\
& $(0.15)$ & $(0.10)$ & $(0.07)$ \\
\hline \multirow{2}{*}{ Internet (portais de notícias e redes sociais) } & 0.49 & 0.23 & $0.31^{*}$ \\
& $(0.27)$ & $(0.17)$ & $(0.11)$ \\
\hline
\end{tabular}




\begin{tabular}{|l|c|c|c|}
\hline & Impactos & Preconceitos & Controle \\
\hline \multirow{2}{*}{ Conhecimento sobre o PBF } & $\begin{array}{c}1.34^{*} \\
(0.28)\end{array}$ & $\begin{array}{c}-0.15 \\
(0.18)\end{array}$ & $\begin{array}{c}0.34 * \\
(0.12)\end{array}$ \\
\hline \multirow{2}{*}{ Beneficiário do PBF } & 0.36 & $-0.69^{*}$ & -0.10 \\
& $(0.22)$ & $(0.17)$ & $(0.11)$ \\
\hline \multirow{2}{*}{ Mora com beneficiário do PBF } & 0.28 & -0.13 & -0.082 \\
& $(0.19)$ & $(0.14)$ & $(0.09)$ \\
\hline \multirow{2}{*}{ Individualismo } & $-1.16^{*}$ & $1.49^{*}$ & $0.57^{*}$ \\
& $(0.22)$ & $(0.14)$ & $(0.10)$ \\
\hline \multirow{2}{*}{ Constante } & $11.0 *$ & $6.62^{*}$ & $4.95^{*}$ \\
& $(0.43)$ & $(0.28)$ & $(0.18)$ \\
\hline $\mathrm{N}$ & 1737 & 1745 & 1765 \\
\hline $\mathrm{R}^{2}$ ajustado & 0.177 & 0.091 & 0.049 \\
\hline
\end{tabular}

Fonte: Pesquisa Quadrimestral Secom-PR - novembro de 2014. Significância: * $p<0.05$.

Nota: Erros-padrão robustos entre parênteses.

A avaliação do governo federal, ser morador do Nordeste e do Sul, a exposição ao Jornal Nacional e o conhecimento sobre o PBF apresentaram uma correlação positiva com a percepção dos impactos positivos do programa. A escolaridade, a renda familiar e o individualismo tiveram uma associação negativa. Esperávamos encontrar um posicionamento mais crítico dos habitantes da região Sul. De todo modo, e embora não tenhamos uma boa explicação para esse resultado, não o vemos como algo inverossímil, já que é possível ser crítico ao programa e, ainda assim, aceitar seus resultados positivos.

A relação entre algumas variáveis e os índices negativos foi menos congruente. Entrevistados brancos tiveram pontuações menores nas visões negativas em relação aos beneficiários e nas críticas à gestão do PBF. Ou seja, esses entrevistados contribuíram para diminuí-las. Ser morador do Sudeste e do Nordeste aumentou a pontuação do índice de preconceito. O resultado era esperado em relação ao primeiro, mas não em relação ao segundo. $\mathrm{O}$ fato de o Nordeste ter uma grande proporção de beneficiários do PBF decorre de sua grande desigualdade social. Talvez o fato de várias pessoas conviverem com beneficiários, mas não receberem os mesmos benefícios, tenha gerado reticências e ressentimentos de uma parte da população residente nos estados da região.

A percepção sobre a falta de oportunidades iguais naturalmente aumenta as chances de reconhecimento dos impactos positivos e de ser favorável ao PBF. Mas estas tendem a ser relações com medidas abstratas e factuais. A relação com o índice de preconceito tem uma natureza distinta, pois elas estão calcadas em mitos sobre o programa (Campello, 2013). Ou seja, embora as críticas levantadas sejam populares, não encontram comprovação empírica (Jannuzzi e Pinto, 2013; Barbosa e Corseuil, 2013; Ribeiro, Shikida e Hillbrecht, 2017). Essa talvez seja a melhor demonstração do que a literatura chama de ambivalência (Feldman e Zaller, 1992).

O fato de o conhecimento sobre o PBF não diminuir o preconceito em relação aos beneficiários reforça essa interpretação. Da maneira como foi construído, o índice tem 
características factuais. Como as visões preconceituosas são fruto dos valores dos entrevistados e não da falta de informação, é aceitável que essa variável não tenha alcançado significância estatística, mesmo que o sinal do coeficiente esteja na direção esperada. No limite, isso significa que a visão sobre o PBF não mudaria tanto, mesmo com políticas educacionais. Trata-se, de forma mais forte, de uma questão de visões de mundo e ideologia, enraizadas em convicções pessoais sustentadas por valores. Esse resultado sugere que mudanças relacionadas à opinião pública não dependem puramente da "educação" ou da quantidade de "informação", mas de mudanças estruturais de longo prazo, que provoquem mudanças no próprio sistema de crença dos indivíduos ${ }^{19}$.

As alegações sobre a falta de controle do PBF também são comuns. Embora parte da crítica contida nesse índice possa ser atribuída a valores, a interpretação dos dados sugere que pode haver elementos factuais. Morar no Nordeste aumenta a pontuação no indicador. Ser beneficiário, ou conhecer um, não diminui as críticas, já que os coeficientes não alcançaram significância estatística. Os sinais negativos das estimativas das variáveis escolaridade e cor sugerem que esse efeito é maior entre as pessoas com menor instrução e não brancas. Ou seja, justamente quem teria maiores chances de receber os benefícios.

\section{Conclusões}

Até hoje, apenas um trabalho analisou como os brasileiros avaliam as políticas que buscam melhorar a vida de cidadãos em condições de vulnerabilidade e se posicionam em relação a estas, como é o caso do PBF (Castro et al., 2009). Estudos como o deste artigo são importantes não apenas pelas consequências sociais, políticas e econômicas desse tipo de programa, mas também pela grande quantidade de trabalhos produzidos internacionalmente sobre os fatores que influenciam a opinião pública a apoiar ou rejeitar políticas que se enquadrariam dentro de um contexto de Estado de bem-estar social.

Embora seja uma importante política de combate à pobreza, com resultados efetivos, as análises apresentadas neste artigo mostram que a opinião pública em relação ao PBF é complexa. O apoio e as avaliações sobre o programa variam muito. Se questionados de modo direto, a maior parte dos brasileiros mostra-se a favor do PBF. Ao mesmo tempo, também critica os beneficiários e a suposta falta de controle do programa. A verdade é que essas críticas podem ter ligação tanto com a experiência concreta dos entrevistados quanto com outros mitos criados em torno do funcionamento do Bolsa Família. Mas, ao contrário do índice de preconceitos, a literatura sobre o programa não nos permite destrinchar o quanto dessas percepções sobre o seu funcionamento encontram respaldo empírico.

De todos os indicadores, foram as variáveis políticas que apresentaram maior coerência e estabilidade: avaliação do governo federal e individualismo. As opiniões sobre

\footnotetext{
19 Agradecemos a um(a) do(a)s pareceristas anônimos da revista Opinião Pública por nos chamar atenção para esse fato.
} 
o PBF estavam fortemente associadas à administração petista. Quanto melhor o juízo sobre o desempenho da ex-presidente, maiores o apoio ao programa e o reconhecimento dos seus impactos positivos, e menores o preconceito em relação aos beneficiários e as críticas ao seu funcionamento. Ao mesmo tempo, quanto maior o individualismo do entrevistado, menores o apoio ao programa e o reconhecimento dos seus impactos positivos, e maiores o preconceito em relação aos beneficiários e as críticas ao seu funcionamento.

$\mathrm{Na}$ literatura internacional, a rejeição dos brancos às políticas de combate à desigualdade social foi demonstrada de diversas formas. A expectativa era de que efeitos semelhantes ocorressem no Brasil. Não encontramos o mesmo cenário, ao menos com os dados utilizados neste artigo. Como discutido anteriormente, uma primeira explicação é a própria limitação do indicador. A simples condição de o entrevistado se declarar branco não deve ser vista como um sinônimo de preconceito aos beneficiários do PBF e de rejeição a programas de combate à pobreza.

Uma segunda explicação seria que os temas e políticas investigados na literatura internacional - gastos com programas de bem-estar social (AuClaire, 1984), motivação dos pobres e gastos governamentais para ajudá-los (Williamson, 1974; Gilens, 1996b), apoio geral aos programas de bem-estar social (Hasenfeld e Rafferty, 1989; Gilens, 1995), políticas públicas para tratamento igualitário aos negros, integração escolar e oportunidades iguais (Tuch e Hughes, 1996) etc. - não seriam semelhantes a um programa de transferência de renda com condicionalidades, como é o caso do PBF, corroborando a interpretação de que as características dos apoiadores dos programas de assistência social variam de acordo com o tipo de ajuda oferecida (Hasenfeld e Rafferty, 1989). Assim, apenas novos estudos, com indicadores mais precisos e confiáveis, poderiam esclarecer o quanto os achados da literatura internacional encontrariam ressonância em um contexto diferente.

Por fim, ressaltamos a necessidade de novos estudos para dirimir as dúvidas e esclarecer alguns pontos que ficaram sem resposta neste artigo. Talvez o seu maior mérito seja a tentativa de analisar um tema bastante complexo e pouquíssimo estudado, que é a opinião pública brasileira sobre uma política pública de combate à pobreza, como é o caso do PBF. Entender os fatores que determinam maior ou menor apoio a essas políticas é importante para que elas continuem a ser implementadas, dado o seu impacto social.

\section{Referências bibliográficas}

AuClaire, P. A. "Public attitudes toward social welfare expenditures". Social Work, vol. 29, no 2, p. $139-144,1984$.

Barbosa, A. L. N. H.; Corseuil, C. H. L. Bolsa Família, escolha ocupacional e informalidade no Brasil. In: Campello, T.; Neri. M. C. (orgs.). Programa Bolsa Família: uma década de inclusão e cidadania. Brasília: Ipea, p. 327-340, 2013. 
BIROLI, F.; MANTOVANI, D. "Disputas, ajustes e acomodações na produção da agenda eleitoral: a cobertura jornalística ao Programa Bolsa Família e as eleições de 2006". Opinião Pública, vol. 16, no 1 , p. 90-116, 2010.

Campbell, A., et al. The American voter: an abridgment. New York: John Wiley \& Sons, 1967.

CAmpello, T. Uma década derrubando mitos e superando expectativas. In: CAmpello, T.; NeRI, M. C. (orgs.). Programa Bolsa Família: uma década de inclusão e cidadania. Brasília: Ipea, p. 15-24, 2013.

Campello, T.; Neri, M. C. Programa Bolsa Família: uma década de inclusão e cidadania. Brasília: Ipea, 2013.

CAnÊdo-Pinheiro, M. "Bolsa Família ou desempenho da economia? Determinantes da reeleição de Lula em 2006". Economia Aplicada, vol. 19, no 1, p. 31-61, 2015.

CAStRo, H. C. O., et al. "Percepções sobre o Programa Bolsa Família na sociedade brasileira". Opinião Pública, vol. 15, no 2, p. 333-355, 2009.

Cavalcanti, D. M.; Costa, E. M.; Silva, J. L. M. "Programa Bolsa Família e o Nordeste: impactos na renda e na educação, nos anos de 2004 e 2006". Revista de Economia Contemporânea, vol. 17, no 1 , p. $99-128,2013$.

CONVERSE, P. E. The nature of belief systems in mass politics. In: APTER, D. E. (org.). Ideology and discontent. New York: The Free Press, p. 206-261, 1964.

CORRÊA, D. S. "Os custos eleitorais do Bolsa Família: reavaliando seu impacto sobre a eleição presidencial de 2006". Opinião Pública, vol. 21, n 3, p. 514-534, 2015.

CORRÊA, D. S. "Transferência de renda e eleições: a trajetória latino-americana". Revista Brasileira de Ciências Sociais, vol. 31, no 90, p. 99-114, 2016.

Craveiro, C. B. A.; Ximenes, D. A. Dez anos do Programa Bolsa Família: desafios e perspectivas para a universalização da educação básica no Brasil. In: CAMPEllo, T.; Neri. M. C. (orgs.). Programa Bolsa Família: uma década de inclusão e cidadania. Brasília: Ipea, p. 109-124, 2013.

DESANTE, C. D. "Working twice as hard to get half as far: race, work ethic, and America's deserving poor". American Journal of Political Science, vol. 57, no 2, p. 342-356, 2013.

ERIKSON, R. S.; MACKUen, M. B.; Stimson, J. A. Public opinion and policy causal flow in a macro system model. In: MANZA, J.; COOK, F. L.; PAGE, B. I. (orgs.). Navigating public opinion: polls, policy, and the future of American democracy. Oxford: Oxford University Press, p. 33-53, 2002.

FARIA, C. A. P. "Uma genealogia das teorias e modelos do Estado de bem-estar social". BIB, n 46, p. 39-71, 1998.

Feldman, S. "Economic individualism and American public opinion". American Politics Quarterly, vol. 11, n० 1 , p. 3-39, 1983.

FELDMAN, S.; ZALLER, J. R. "The political culture of ambivalence: ideological responses to the welfare state". American Journal of Political Science, vol. 36, no 1, p. 268-307, 1992.

Fox, C. "The changing color of welfare? How whites' attitudes toward Latinos influence support for welfare". American Journal of Sociology, vol. 110, no 3, p. 580-625, 2004.

GILENS, M. "Racial attitudes and opposition to welfare". The Journal of Politics, vol. 57, no 4, p. 994$1.014,1995$. 


\begin{abstract}
"Race and poverty in America: public misperceptions and the American news media". Public Opinion Quarterly, vol. 60, no 4, p. 515-541, 1996a.

GILENS, M. "'Race coding' and white opposition to welfare". American Political Science Review, vol. 90, no 3, p. 593-604, 1996b.
\end{abstract}

HASENFELD, Y.; RAfFerTY, J. A. "The determinants of public attitudes toward the welfare state". Social Forces, vol. 67, no 4, p. 1.027-1.048, 1989.

Hoffmann, R. Transferências de renda e desigualdade no Brasil (1995-2011). In: CAMPELLO, T.; NERI, M. C. (orgs.). Programa Bolsa Família: uma década de inclusão e cidadania. Brasília: Ipea, p. 207$216,2013$.

Hunter, W.; Power, T. J. "Rewarding Lula: Executive Power, social policy, and the Brazilian elections of 2006". Latin American Politics and Society, vol. 49, p. 1-30, 2007.

JACKMAN, M. R. "General and applied tolerance: does education increase commitment to racial integration?". American Journal of Political Science, vol. 22, no 2, p. 302-324, 1978.

. "Education and policy commitment to racial integration". American Journal of Political Science, vol. 25, no 2, p. 256-269, 1981.

JACKMAN, M. R.; MUHA, M. J. "Education and intergroup attitudes: moral enlightenment, superficial democratic commitment, or ideological refinement?". American Sociological Review, vol. 49, n 6, p. 751-769, 1984.

JAnnuzzi, P. M.; PInTo, A. R. Bolsa Família e seus impactos nas condições de vida da população brasileira: uma síntese dos principais achados da pesquisa de avaliação de impacto do Bolsa Família II. In: CAmpello, T.; Neri, M. C. (orgs.). Programa Bolsa Família: uma década de inclusão e cidadania. Brasília: Ipea, p. 179-192, 2013.

LEWIS-BECK, M. S., et al. The American voter revisited. Ann Arbor: The University of Michigan Press, 2008.

Licio, E. C.; Rennó, L.; CASTRO, H. C. O. "Bolsa Família e voto na eleição presidencial de 2006: em busca do elo perdido". Opinião Pública, vol. 15, no 1, p. 31-54, 2009.

Lignani, J. B., et al. "Changes in food consumption among the Programa Bolsa Família participant families in Brazil". Public Health Nutrition, vol. 14, no 5, p. 785-792, 2010.

MANZA, J.; COOK, F. L. The impact of public opinion on public policy: the state of the debate. In: MANZA, J.; COOK, F. L.; PAGE, B. I. (orgs.). Navigating public opinion: polls, policy, and the future of American democracy. Oxford: Oxford University Press, p. 17-32, 2002.

MARQUES, A. C. S. "A deliberação a longo prazo no espaço de visibilidade mediada: o Bolsa-Família na mídia impressa e televisiva". Estudos em Jornalismo e Mídia, vol. 7, no 2, p. 273-285, 2010.

MARQUeS, A. C. S.; MAIA, R. C. M. Deliberation and political socialization: poor women discuss published opinions about Brazilian income transfer program. In: MAIA, R. C. M. Deliberation, the media and political talk. New York: Hamptom Press, p. 227-254, 2012.

Melo, R. M. S.; DuARTE, G. B. "Impacto do Programa Bolsa Família sobre a frequência escolar: o caso da agricultura familiar no Nordeste do Brasil". Revista de Economia e Sociologia Rural, vol. 48, no 3, p. 635-656, 2010.

Neto, R. M. S. Impacto do Programa Bolsa Família sobre a frequência à escola: estimativas a partir de informações da pesquisa nacional por amostra de domicílio (PNAD). In: CASTRO, J. A.; MODESTO, L. (orgs.). Bolsa Família 2003-2010: avanços e desafios. Brasília: Ipea, p. 53-72, 2010. 
Nicolau, J.; PeIXoto, V. Uma disputa em três tempos: uma análise das bases municipais das eleições presidenciais de 2006. Anais do XXXI Encontro Anual da Anpocs. Caxambu (MG), 2007.

PIRES, A. "O Programa Bolsa Família no contexto das políticas de proteção dos Estados de bem-estar social: apontamentos para discussão". Impulso, vol. 23, nº 58, p. 91-101, 2013.

Ribeiro, F. G.; Shikida, C.; Hillbrecht, R. O. "Bolsa Família: um survey sobre os efeitos do programa de transferência de renda condicionada do Brasil". Estudos Econômicos, vol. 47, no 4, p. 805-862, 2017.

Rocha, S. "O Programa Bolsa Família: evolução e efeitos sobre a pobreza". Economia e Sociedade, vol. 20, no 1, p. 113-139, 2011.

SKOCPOL, T. "Sustainable social policy: fighting poverty without poverty programs". The American Prospect, no 2, p. 58-70, 1990.

. Targeting within universalism: politically viable policies to combat poverty in the United States. In: JENCKS, C.; PETERSON, P. (orgs.). The urban underclass. Washington, DC: Brookings Institution, p. 411-436, 1991.

SOARES, F. V.; RIBAS, R. P.; OsóRIO, R. G. "Evaluating the impact of Brazil's Bolsa Família: cash transfer programmes in comparative perspective". IPC Evaluation Note, International Poverty Centre, Brasília, nº 1, 2007.

SOARES, G. A. D.; TERRON, S. L. "Dois Lulas: a geografia eleitoral da reeleição (explorando conceitos, métodos e técnicas de análise geoespacial)". Opinião Pública, vol. 14, no 2, p. 269-301, 2008.

SOARES, S.; SÁtYro, N. O Programa Bolsa Família: desenho institucional e possibilidades futuras. In: CASTRO, J. A.; Modesto, L. (orgs.). Bolsa Família 2003-2010: avanços e desafios. Brasília: Ipea, 2010.

SOARES, S., et al. Os impactos do benefício do Programa Bolsa Família sobre a desigualdade e a pobreza. In: CASTRO, J. A.; MODESTO, L. (orgs.). Bolsa Família 2003-2010: avanços e desafios. Brasília: Ipea, 2010.

Terron, S. L.; SoARes, G. A. D. "As bases eleitorais de Lula e do PT: do distanciamento ao divórcio". Opinião Pública, vol. 16, no 2, p. 310-337, 2010.

TUCH, S. A. "Whites' racial policy attitudes in the twenty-first century: the continuing significance of racial resentment". The Annals of the American Academy of Political and Social Science, vol. 634, no 1 , p. 134-152, 2011.

TUCH, S. A.; HugheS, M. "Whites' racial policy attitudes". Social Science Quarterly, vol. 77, no 4, p. 723-745, 1996.

WEAVER, R. K. Polls, priming, and the politics of welfare reform. In: MANZA, J.; CoOK, F. L.; PAGE, B. I. (orgs.). Navigating public opinion: polls, policy, and the future of American democracy. Oxford: Oxford University Press, p. 106-123, 2002.

Williamson, J. B. "Beliefs about the motivation of the poor and attitudes toward poverty policy". Social Problems, vol. 21, n 5, p. 634-648, 1974.

ZalleR, J. R. The nature and origins of mass opinion. Cambridge: Cambridge University Press, 1992.

ZALleR, J. R.; PRICE, V. "Who gets the news? Alternative measures of news reception and their implications for research". Public Opinion Quarterly, vol. 57, p. 133-164, 1993. 
Zucco, C. "The president's 'new' constituency: Lula and the pragmatic vote in Brazil's 2006 presidential election". Journal of Latin American Studies, vol. 40, p. 29-49, 2008.

Zucco, C. "When payouts pay off: conditional cash transfers and voting behavior in Brazil 2002-10". American Journal of Political Science, vol. 57, no 4, p. 810-822, 2013.

. "The impacts of conditional cash transfers in four presidential elections (2002-2014)". Brazilian Political Science Review, vol. 9, nº 1, p. 135-149, 2015.

\begin{abstract}
Brazilian public opinion on the Bolsa Familia Program and its beneficiaries

This article analyzes where Brazilians stand in relation to the Bolsa Família Program (BFP) and its beneficiaries. The data are from a national public opinion survey commissioned by The Secretariat for Social Communication of the Presidency of the Republic (Secom/PR). The results of a multinomial logistic regression regarding the chances that people will support the BFP have shown that support grows among those with more positive evaluations of the federal government and higher levels of information about the program, as well as among those connected to or in contact with beneficiaries; support wanes depending on schooling and family income, not to mention the individualism of the interviewees. Ambivalences appear when the analyses turn to opinions on the management of Bolsa Família and its beneficiaries. OLS regressions, estimated to assess the opinions on the positive impacts of the BFP and the alleged lack of regulation of and control over the program and its beneficiaries, have shown that more knowledge about the program does not diminish negative views of the beneficiaries or management and oversight of the program. Surprisingly, these critical views are present even among those groups of people most likely to receive Bolsa Família resources, such as the less educated, people of color, and residents of the Northeast.
\end{abstract}

Keywords: Bolsa Família; public opinion; individualism; economic self-interest; racial attitudes

\title{
Resumen
}

El Programa Bolsa Familia y sus beneficiarios en la opinión pública brasileña

El artículo analiza cómo los brasileños se posicionan en relación al Programa Bolsa Familia (PBF) y sus beneficiarios. Los datos son de una encuesta nacional de opinión pública, encargada por la Secretaría de Comunicación Social de la Presidencia de la República (Secom/PR). Los resultados de un modelo logístico multinomial sobre las posibilidades de apoyo al PBF mostraron que ellas crecen con la evaluación positiva del gobierno federal, el nivel de información sobre el programa y el contacto con beneficiarios, pero caen con la escolaridad, la renta familiar y el nivel de individualismo de los entrevistados. Las ambivalencias aparecen cuando los análisis se vuelven a las opiniones sobre la gestión del Bolsa Familia y sus beneficiarios en particular. Regresiones a través de MQO, estimadas para evaluar las opiniones sobre los impactos positivos del PBF, la supuesta falta de control del programa y los beneficiarios, mostraron que poseer más conocimiento sobre el programa no disminuye las visiones negativas sobre los beneficiarios o las críticas en relación a su control. De manera sorprendente, estas visiones críticas están presentes incluso entre grupos de personas que tendrían mayores posibilidades de recibir los recursos del Bolsa Familia, como los menos escolarizados, no blancos y moradores del Nordeste.

Palabras clave: Bolsa Familia; opinión pública; el individualismo; autointerés económico; actitudes raciales

\section{Résumé}

Le programme Bolsa Família et ses bénéficiaires dans I'opinion publique brésilienne

L'article analyse la position des Brésiliens par rapport au programme Bolsa Família (PBF) et à ses bénéficiaires. Les données proviennent d'un sondage d'opinion national commandé par le Secrétariat à la Communication Sociale de la Présidence de la République (Secom/PR). Les résultats d'un modèle logistique multinomial sur les chances de soutenir le PBF ont montré qu'elles augmentaient avec 
l'évaluation positive du gouvernement fédéral, le niveau d'information sur le programme et le contact avec les bénéficiaires, mais qu'elles chutaient à cause de la scolarité, du revenu familial et du niveau de l'individualisme des personnes interviewées. Des ambivalences apparaissent lorsque les analyses se tournent vers les avis sur la gestion du Bolsa Família et sur ses bénéficiaires en particulier. Des régressions via OLS, estimées pour évaluer les opinions sur les impacts positifs du PBF, le prétendu manque de contrôle du programme et des bénéficiaires, ont montré qu'avoir plus de connaissances sur le programme ne minimisait pas les opinions négatives sur les bénéficiaires ni les critiques concernant son contrôle. Étonnamment, ces points de vue critiques sont présents même parmi les groupes de personnes qui seraient plus susceptibles de recevoir des ressources du Bolsa Família, tels que les moins éduqués, les non-blancs et les habitants du Nord-Est.

Mots-clés: Bolsa Família; opinion publique; individualisme; interet economique personnel; attitudes raciales

Artigo submetido à publicação em 16 de abril de 2019. Versão final aprovada em 31 de outubro de 2019.

Opinião Pública adota a licença Creative Commons CC-BY. 